\title{
Beta blocker use in subjects with type 2 diabetes mellitus and systolic heart failure does not worsen glycaemic control
}

Bryan Wai ${ }^{1,2}$, Leighton G Kearney ${ }^{1,2}$, David L Hare ${ }^{1,2}$, Michelle Ord ${ }^{1}$, Louise M Burrell ${ }^{1,2}$ and Piyush M Srivastava ${ }^{1,2^{*}}$

\begin{abstract}
Background: The prognostic benefits of beta-blockers (BB) in patients with systolic heart failure (SHF) are known but despite this, in patients with diabetes they are underutilized. The aim of this study was to assess the effect of beta-blockers (BB) on glycaemic control in patients with Type 2 Diabetes (T2DM) and systolic heart failure (SHF) stratified to beta-1 selective (Bisoprolol) vs. nonselective BB (Carvedilol).

Methods: This observational, cohort study was conducted in patients with T2DM and SHF attending an Australian tertiary teaching hospital's heart failure services. The primary endpoint was glycaemic control measured by glycosylated haemoglobin ( $\mathrm{HbA1c}$ ) at initiation and top dose of BB. Secondary endpoints included microalbuminuria, changes in lipid profile and estimated glomerular filtration rate (eGFR).

Results: 125 patients were assessed. Both groups were well matched for gender, NYHA class and use of guideline validated heart failure and diabetic medications. The mean treatment duration was $1.9 \pm 1.1$ years with carvedilol and $1.4 \pm 1.0$ years with bisoprolol $(p=n s)$. The carvedilol group achieved a reduction in $\mathrm{HbA1c}(7.8 \pm 0.21 \%$ to $7.3 \pm 0.17 \%, p=0.02)$ whereas the bisoprolol group showed no change in HbA1c $(7.0 \pm 0.20 \%$ to $6.9 \pm 0.23 \%, p=$ 0.92). There was no significant difference in the change in $\mathrm{HbA} 1 \mathrm{c}$ from baseline to peak BB dose in the carvedilol group compared to the bisoprolol group. There was a similar deterioration in eGFR, but no significant changes in lipid profile or microalbuminuria in both groups ( $p=n s$ ).
\end{abstract}

Conclusion: BB use did not worsen glycaemic control, lipid profile or albuminuria status in subjects with SHF and T2DM. Carvedilol significantly improved glycemic control in subjects with SHF and T2DM and this improvement was non significantly better than that obtained with bisoprolol. BB's should not be withheld from patients with T2DM and SHF.

Keywords: Beta-blockers, Diabetes, Systolic heart failure, Glycaemic control

\section{Background}

The prognostic benefits of beta-blockers $(\mathrm{BB})$ in patients with systolic heart failure (SHF) are known $[1,2]$ but despite this, patients with diabetes have been identified as receiving suboptimal treatment with $\mathrm{BB}[3,4]$. The prevalence of SHF in patients with T2DM is 12\% whilst in patients with left ventricular systolic dysfunction $6-25 \%$ have T2DM [5]. It would seem clear that in the management of patients with both T2DM and SHF, use of beta-blockers whilst maintaining good glycaemic

\footnotetext{
* Correspondence: Piyush.srivastava@austin.org.au

${ }^{1}$ Department of Cardiology, Austin Health, Heidelberg, VIC, Australia

Full list of author information is available at the end of the article
}

control is paramount to improved clinical outcomes [6-8]. In hypertensive subjects with T2DM without SHF, carvedilol has been shown to have favorable effects on glycaemic control in comparison with metoprolol tartrate [9].

We aimed to assess the glycaemic control of patients with T2DM and SHF treated with BB in a tertiary teaching hospital and the differential effects of a nonselective BB (carvedilol) versus a $\beta 1$ selective BB (bisoprolol) on glycaemic control, renal function, albuminuria and lipid profile. 


\section{Methods}

\section{Patients}

Consecutive patients that were referred following an index hospitalization with decompensated SHF and T2DM to our multidisciplinary heart failure clinic were enrolled. Patients were followed up prospectively.

\section{Heart failure management}

Patients received either carvedilol or bisoprolol and the doses were titrated to a maximal tolerated dose (target of $10 \mathrm{mg}$ of bisoprolol or $50 \mathrm{mg}$ of carvedilol per day). The choice of beta-blocker was left to the discretion of the treating cardiologist, with other heart failure management utilization as per accepted guidelines [2] Patients included were not on beta-blockers prior to index hospitalization.

\section{Diabetes management}

Patients were managed for their diabetes by their primary care and specialist diabetes physician. The number of anti-diabetic medications in both groups during the follow-up period did not change.

\section{Measured variables}

SHF was defined as presence of symptoms and signs of heart failure and left ventricular ejection fraction less than 50\%. New York Heart Association Class (NYHA) was recorded at the first outpatient visit along with collection of serum and urine samples at commencement and within 3 months of achieving peak tolerated dose of BB. Glycaemic control was assessed by glycosylated haemoglobin (HbA1c) which is measured by automated HPLC (Bio-Rad Laboratories, California, USA). Renal function by estimated Glomerular Filtration Rate (eGFR) and albuminuria by using the ratio of urinary albumin concentration to urinary creatinine concentration (ACR). Microalbuminuria was defined as ACR greater than $30 \mathrm{mg} / \mathrm{g}$ and less than $300 \mathrm{mg} / \mathrm{g}$. To assess changes in lipid profile, fasting total cholesterol (TC), high-density lipoprotein (HDL) and lowdensity lipoprotein (LDL) and triglyceride (TG) level were measured according to previously published methods [10].

\section{Statistical analysis}

Continuous data are presented as mean \pm standard deviation and categorical data as $\mathrm{n}(\%)$. Changes in HbA1c, eGFR, microalbuminuria and lipid profile were examined using t-tests. Categorical variables were compared using Fisher's exact test. Statistical significance was taken as $p<0.05$.

\section{Results}

Data from a total of 125 patients with SHF and T2DM was analyzed ( $\mathrm{n}=80$ carvedilol, $\mathrm{n}=45$ bisoprolol). The mean treatment duration from baseline to peak BB dose was $1.9 \pm 1.1$ years with carvedilol and $1.4 \pm 1.0$ years with bisoprolol ( $p=\mathrm{ns}$ ). The mean peak dose of carvedilol was $26.5 \pm 21.1 \mathrm{mg} /$ day and bisoprolol was $5.8 \pm$ $3.0 \mathrm{mg} /$ day. Both groups were well matched for gender (majority male), NYHA class, and use of guideline validated therapies i.e. renin angiotensin system inhibitors, diuretics, spironolactone and diabetes treatment (diet, oral hypoglycaemics and/or insulin). (Table 1)

For the primary endpoint, glycaemic control improved in the carvedilol group but no significant change was noted in the bisoprolol group (Table 2). No significant difference was seen between the changes in HbA1c in the carvedilol group vs. bisoprolol group $(-0.5 \pm 1.4 \%$ vs. $0.2 \pm 1.3 \%$; $p=0.09$ ) (Figure 1). Both groups had significant reductions in eGFR from baseline to peak BB dose, but with no significant difference in this reduction between the carvedilol and bisoprolol groups. The proportion of patients with microalbuminuria remained the same in both groups for the duration of the study. There were no significant differences in the lipid profile between the two groups for the duration of the study.

\section{Discussion}

The major finding of this study is that $\mathrm{BB}$ use did not worsen glycaemic control, lipid profile nor albuminuria status in patients with T2DM and SHF, suggesting that these medications should not be withheld in this highrisk group. This is in contradiction to the GEMINI study, where hypertensive T2DM patients randomized to carvedilol (nonselective $\mathrm{BB}$ ) did not have a significant

Table 1 Patient's baseline characteristics

\begin{tabular}{|c|c|c|c|}
\hline & $\begin{array}{c}\text { Carvedilol } \\
(\mathrm{n}=80)\end{array}$ & $\begin{array}{l}\text { Bisoprolol } \\
(n=45)\end{array}$ & $p$-value \\
\hline \multicolumn{4}{|l|}{ Demographics } \\
\hline Male & $62(78 \%)$ & $34(76 \%)$ & 0.83 \\
\hline Age (years) & $71.0 \pm 9.7$ & $70.7 \pm 10.8$ & 0.89 \\
\hline NYHA (mean) & $2.1 \pm 0.7$ & $2.1 \pm 0.6$ & 0.90 \\
\hline NYHA Class I & $14(18 \%)$ & $5(11 \%)$ & \\
\hline NYHA Class $\|$ & $45(56 \%)$ & $30(67 \%)$ & \\
\hline NYHA Class III & $18(22 \%)$ & $10(22 \%)$ & \\
\hline NYHA Class IV & $3(4 \%)$ & 0 & \\
\hline \multicolumn{4}{|l|}{ Diabetic Medications } \\
\hline Diet & $12(15 \%)$ & $5(11 \%)$ & 0.60 \\
\hline Oral hypoglycaemic & $49(61 \%)$ & $27(60 \%)$ & 1.00 \\
\hline Insulin & $19(24 \%)$ & $13(29 \%)$ & 0.53 \\
\hline \multicolumn{4}{|c|}{ Heart Failure Medications } \\
\hline ACEI & $61(76 \%)$ & $33(73 \%)$ & 0.83 \\
\hline ARB & $24(30 \%)$ & $14(31 \%)$ & 1.00 \\
\hline$A C E I$ and $A R B$ & $9(11 \%)$ & $4(9 \%)$ & 0.77 \\
\hline Spironolactone & $50(62 \%)$ & $26(58 \%)$ & 0.70 \\
\hline Thiazide & $11(14 \%)$ & $9(20 \%)$ & 0.45 \\
\hline
\end{tabular}

$\mathrm{ACEI}=$ Angiotensin Converting Enzyme Inhibitor, $\mathrm{ARB}=$ Angiotensin Receptor Blocker 
Table 2 Glycaemic control, lipid profile and renal function in both groups at baseline and at peak beta-blocker dose

\begin{tabular}{|c|c|c|c|c|c|c|}
\hline & \multicolumn{3}{|c|}{ Carvedilol } & \multicolumn{3}{|c|}{ Bisoprolol } \\
\hline & Baseline & Peak BB & $p$-value & Baseline & Peak BB & $p$-value \\
\hline \multicolumn{7}{|c|}{ Glycaemic control } \\
\hline $\mathrm{HbA} 1 \mathrm{c}$ & $7.7 \pm 1.5$ & $7.2 \pm 1.2$ & 0.02 & $7.0 \pm 1.2$ & $6.9 \pm 1.3$ & 0.92 \\
\hline \multicolumn{7}{|c|}{ Lipid Profile } \\
\hline $\mathrm{TC} / \mathrm{HDL}$ & $4.1 \pm 1.0$ & $3.7 \pm 1.1$ & 0.07 & $3.1 \pm 1.0$ & $3.0 \pm 1.2$ & 0.67 \\
\hline LDL/HDL & $2.2 \pm 0.9$ & $2.0 \pm 0.9$ & 0.08 & $1.5 \pm 0.7$ & $1.5 \pm 1.0$ & 0.83 \\
\hline TG & $1.9 \pm 1.2$ & $2.0 \pm 1.5$ & 0.66 & $1.6 \pm 1.2$ & $1.5 \pm 0.9$ & 0.52 \\
\hline \multicolumn{7}{|c|}{ Renal function } \\
\hline eGFR & $53.6 \pm 27.8$ & $48.4 \pm 27.4$ & 0.01 & $60.4 \pm 24.2$ & $51.1 \pm 26.9$ & $<0.01$ \\
\hline$A C R$ & $0.7 \pm 0.8$ & $0.6 \pm 0.72$ & 0.6 & $0.9 \pm 0.9$ & $0.7 \pm 1.0$ & 1.00 \\
\hline
\end{tabular}

change in $\mathrm{HbA1c}$ whereas patients on metoprolol tartrate (selective $\beta 1 \mathrm{BB}$ ) had a significant increase in HbA1c [9]. Futhermore, in a sub-analysis of the GEMINI study an increase in insulin resistance as measured by homeostasis model assessment-insulin resistance (HOMA-IR) was found in patients treated with metoprolol compared to carvedilol[11]. In another study, metoprolol use in patients with type 2 diabetes mellitus was shown to be associated with a significant reduction in insulin-stimulated endothelial function where as this function was preserved with carvedilol use [12] One proposed mechanism for this was that selective $\beta 1$ BB's such as atenolol and metoprolol may cause vasoconstriction, decreased peripheral blood flow and may exacerbate insulin resistance [13], whereas the $\alpha$ adrenergic blocking effect of carvedilol may allow greater peripheral blood flow and hence increased utilization of glucose. . This differential effect on glycaemic control seen in hypertensive diabetics may not be applicable to patients with systolic heart failure due to their overactive sympathetic tone. In addition we found that there was a significant improvement in glycaemic control between baseline to peak $\mathrm{BB}$ dose within the carvedilol group but not within the bisoprolol group. Whilst there was also a strong trend for better glycaemic control in the carvedilol group compared to the bisoprolol group, this did not quite reach statistical significance. This result could possibly have been biased by different baseline HbA1c levels between the two groups and therefore does not provide absolute evidence for the differential effects on glycaemic control between carvedilol and bisoprolol.

The GEMINI study also showed that patients on carvedilol had a greater reduction in microalbuminuria when compared to patients taking metoprolol [14]. Such differences were not seen in our study. This could be
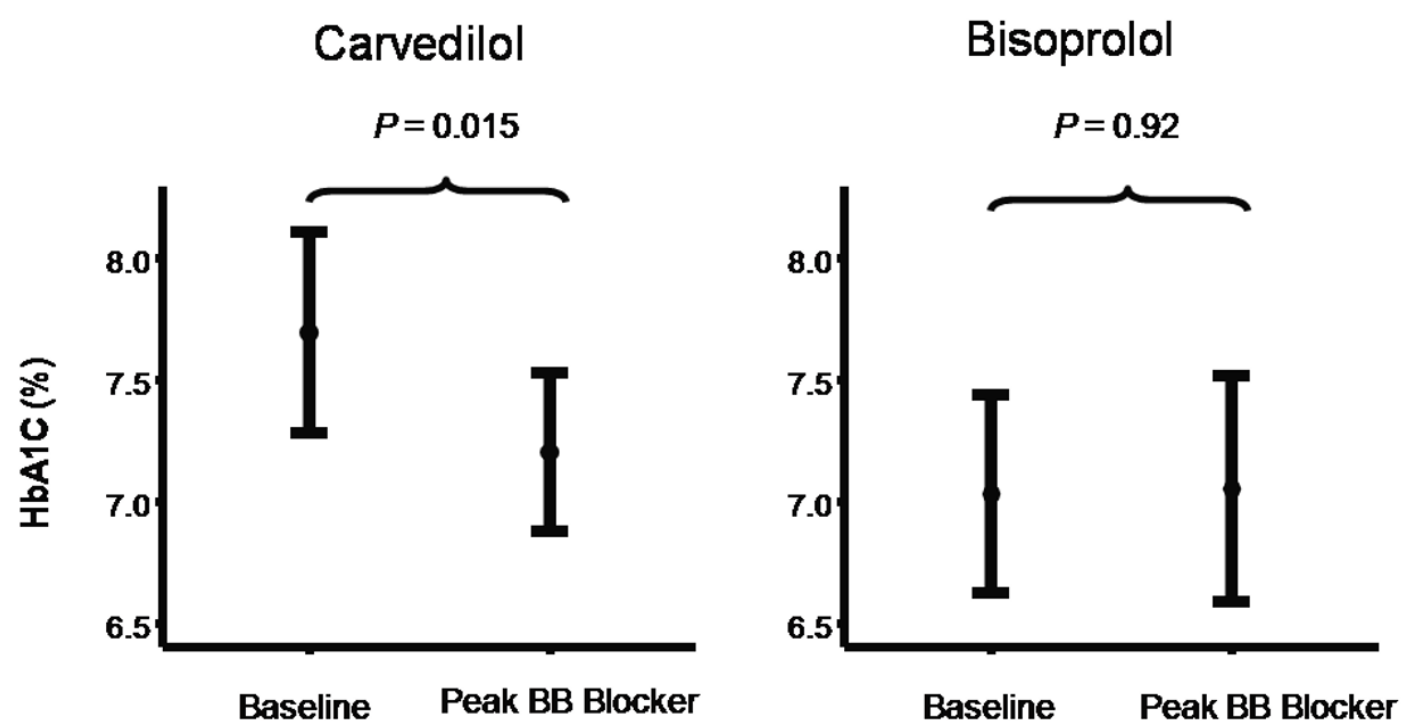

Figure 1 Mean $\mathrm{HbA} 1 \mathrm{c} \pm$ standard deviation at baseline and at peak beta-blocker dose. 
explained by the fact that there is a known higher incidence of microalbuminuria in patients with SHF [15]. Half of the patients in our study had microalbuminuria for the duration of the study, which is a higher proportion than found in the general population of patients with T2DM. The National Health and Nutrition Examination Survey found microalbuminuria in 29\% of patients with diabetes mellitus [16] whereas the PREVEND study noted only $16 \%$ of patients with diabetes mellitus had microalbuminuria [17]. The higher incidence of microalbuminuria in our study is likely to be mediated via impairment of endothelial function[15,18]. A recent study by Jawa et al. in African American subjects with T2DM and hypertension suggested that there was an improvement in endothelial function and albuminuria with commencement of carvedilol but without significant change in albuminuria with metoprolol [19]. In contrast, a recent study in in patients with mild heart failure (16\% diabetic) failed to show a change in endothelium-dependent vasodilatation when the betablocker was changed from carvedilol to metoprolol succinate or tartrate [20]. We did not find any significant changes in albuminuria over the follow-up period in either group.

A concern of treating physicians has often been that $\mathrm{BB}$ use would lead to elevation of triglycerides and lowering of HDL. A study by Pollare et al. demonstrated significant elevation in LDL to HDL ratio and triglyceride levels with the use of metoprolol or atenolol [21]. In a more contemporary cohort, beta-blocker use was not associated with a deterioration in lipid profile but suggest greater statin use with metoprolol when compared to carvedilol[22]. In our study, no worsening in lipid profiles was seen in either group of patients whilst on BB. This might be related to a greater use of statins amongst our cohort of patients.

Traditional teaching for T2DM has been that BB may worsen hypoglycaemic awareness, glycaemic control and lipid metabolism and should be used with caution. However, the prognosis of patients that develop SHF is poor and is markedly improved by appropriate BB therapy. Although the use of beta-blockers in T2DM and SHF has not been specifically studied, meta-analyses of largescale clinical trials have demonstrated the prognostic benefit of beta-blockers in SHF patients who also have diabetes mellitus [23]. Indeed to the authors knowledge there is only one other study that has compared carvedilol to bisoprolol in patients with SHF where, retrospectively after 18 months of follow up, no significant differences were found in survival or cardiac morbidity [24] In addition, strict glycaemic control is essential to the management of patients with diabetes mellitus. In the United Kingdom Prospective Diabetic Study, lowering of $\mathrm{HbA} 1 \mathrm{c}$ toward $6 \%$ resulted in significant reductions of micro vascular and macro vascular complications and death related to T2DM, including SHF [8]. Furthermore, poor glycaemic control is associated with increased incidence of heart failure, hospitalization and death [7]. It is clear that in the management of patients with T2DM and SHF, the use of beta-blockers whilst maintaining good glycaemic control is important.

\section{Limitations}

This study was an observational cohort study and not a randomised control trial. Hence the choice of beta blocker and diabetic therapies were left to the treating cardiologist and endocrinologist and thus could be a possible source of bias. Despite this, both cohorts were well matched at baseline for diabetes and heart failure treatment. Nevertheless, because the initial $\mathrm{HbA1c}$ readings were different between the two groups, it is difficult to draw an absolute conclusion regarding the differential effects of carvedilol and metoprolol. (selective vs. nonselective)

\section{Conclusion}

In conclusion, $\mathrm{BB}$ use did not worsen glycaemic control, lipid profile nor albuminuria status in patients with T2DM and SHF, suggesting that these medications should not be withheld in this group of patients. Carvedilol significantly improved glycemic control in patients with T2DM and SHF and that this improvement was non significantly better than that obtained with bisoprolol.

\section{Abbreviations}

BB: Beta blocker; SHF: Systolic heart failure; T2DM: Type II diabetes mellitus; HbA1c: Glycosylated haemoglobin; eGFR: Estimated glomerular filtration rate; NYHA: New York heart association; ACR: Albumin creatinine ratio; TC: Total cholesterol; HDL: High density lipoprotein; LDL: Low density lipoprotein; TG: Triglycerides.

\section{Acknowledgements}

$\mathrm{Nil}$

\section{Author details}

'Department of Cardiology, Austin Health, Heidelberg, VIC, Australia. ${ }^{2}$ Department of Medicine, University of Melbourne, Austin Health, Heidelberg, VIC, Australia.

\section{Authors' contributions}

BW, LGK, MO, PMS: Conception, data acquisition, analysis, drafting and revising manuscript. DLH, LMB: Data acqusition, analysis, drafting and revising manuscript. All authors read and approved the final manuscript.

\section{Competing interests}

The authors declare that they have no competing interests.

Received: 22 November 2011 Accepted: 14 February 2012

Published: 14 February 2012

\section{References}

1. Packer M, Coats AJ, Fowler MB, Katus HA, Krum H, Mohacsi P, Rouleau JL, Tendera $\mathrm{M}$, Castaigne A, Roecker EB, et al: Effect of carvedilol on survival in severe chronic heart failure. N Engl J Med 2001, 344:1651-1658. 
2. Hunt SA: ACC/AHA 2005 guideline update for the diagnosis and management of chronic heart failure in the adult: a report of the American College of Cardiology/American Heart Association Task Force on Practice Guidelines (Writing Committee to Update the 2001 Guidelines for the Evaluation and Management of Heart Failure). J Am Coll Cardiol 2005, 46:e1-82.

3. Yilmaz MB, Refiker M, Guray Y, Guray U, Altay H, Demirkan B, Caldir V, Korkmaz S: Prescription patterns in patients with systolic heart failure at hospital discharge: why beta blockers are underprescribed or prescribed at low dose in real life? Int J Clin Pract 2007, 61:225-230.

4. ASHP therapeutic position statement on the use of beta-blockers in survivors of acute myocardial infarction. Am J Health Syst Pharm 2002, 59:2226-2232.

5. MacDonald MR, Petrie MC, Hawkins NM, Petrie JR, Fisher M, McKelvie R, Aguilar D, Krum H, McMurray JJ: Diabetes, left ventricular systolic dysfunction, and chronic heart failure. Eur Heart J 2008, 29:1224-1240.

6. Doehner W, Rauchhaus M, Ponikowski P, Godsland IF, von Haehling S, Okonko DO, Leyva F, Proudler AJ, Coats AJ, Anker SD: Impaired insulin sensitivity as an independent risk factor for mortality in patients with stable chronic heart failure. J Am Coll Cardiol 2005, 46:1019-1026.

7. Iribarren C, Karter AJ, Go AS, Ferrara A, Liu JY, Sidney S, Selby JV: Glycemic control and heart failure among adult patients with diabetes. Circulation 2001, 103:2668-2673.

8. Stratton IM, Adler Al, Neil HA, Matthews DR, Manley SE, Cull CA, Hadden D, Turner RC, Holman RR: Association of glycaemia with macrovascular and microvascular complications of type 2 diabetes (UKPDS 35): prospective observational study. Bmj 2000, 321:405-412.

9. Bakris GL, Fonseca V, Katholi RE, McGill JB, Messerli FH, Phillips RA, Raskin P, Wright JT Jr, Oakes R, Lukas MA, et al: Metabolic effects of carvedilol vs metoprolol in patients with type 2 diabetes mellitus and hypertension: a randomized controlled trial. Jama 2004, 292:2227-2236.

10. Srivastava PM, Thomas MC, Calafiore P, Maclsaac RJ, Jerums G, Burrell LM: Diastolic dysfunction is associated with anaemia in patients with Type ॥ diabetes. Clin Sci (Lond) 2006, 110:109-116.

11. Fonseca V, Bakris GL, Bell DS, McGill JB, Raskin P, Messerli FH, Phillips RA, Katholi RE, Wright JT Jr, Waterhouse B, et al: Differential effect of betablocker therapy on insulin resistance as a function of insulin sensitizer use: results from GEMINI. Diabet Med 2007, 24:759-763.

12. Kveiborg B, Hermann TS, Major-Pedersen A, Christiansen B, Rask-Madsen C Raunso J, Kober L, Torp-Pedersen C, Dominguez H: Metoprolol compared to carvedilol deteriorates insulin-stimulated endothelial function in patients with type 2 diabetes - a randomized study. Cardiovasc Diabetol 2010, 9:21.

13. Jacob S, Rett K, Wicklmayr M, Agrawal B, Augustin HJ, Dietze GJ: Differential effect of chronic treatment with two beta-blocking agents on insulin sensitivity: the carvedilol-metoprolol study. J Hypertens 1996, 14:489-494.

14. Bakris GL, Fonseca V, Katholi RE, McGill JB, Messerli F, Phillips RA, Raskin P, Wright JT Jr, Waterhouse B, Lukas MA, et al: Differential effects of betablockers on albuminuria in patients with type 2 diabetes. Hypertension 2005, 46:1309-1315.

15. Arnold JM, Yusuf S, Young J, Mathew J, Johnstone D, Avezum A, Lonn E, Pogue J, Bosch J: Prevention of Heart Failure in Patients in the Heart Outcomes Prevention Evaluation (HOPE) Study. Circulation 2003 107:1284-1290.

16. Jones CA, Francis ME, Eberhardt MS, Chavers B, Coresh J, Engelgau M, Kusek JW, Byrd-Holt D, Narayan KM, Herman WH, et al: Microalbuminuria in the US population: third National Health and Nutrition Examination Survey. Am J Kidney Dis 2002, 39:445-459.

17. de Jong PE, Hillege HL, Pinto-Sietsma SJ, de Zeeuw D: Screening for microalbuminuria in the general population: a tool to detect subjects at risk for progressive renal failure in an early phase? Nephrol Dial Transplant 2003, 18:10-13.

18. Kirpichnikov D, McFarlane SI, Sowers JR: Heart failure in diabetic patients: utility of beta-blockade. J Card Fail 2003, 9:333-344.

19. Jawa A, Nachimuthu S, Pendergrass M, Asnani S, Fonseca V: Beta-blockers have a beneficial effect upon endothelial function and microalbuminuria in African-American subjects with diabetes and hypertension. J Diabetes Complications 2008, 22:303-308.

20. Falskov B, Hermann TS, Raunso J, Christiansen B, Rask-Madsen C, MajorPedersen A, Kober L, Torp-Pedersen C, Dominguez H: Endothelial function is unaffected by changing between carvedilol and metoprolol in patients with heart failure-a randomized study. Cardiovasc Diabetol 2011, 10:91.

21. Pollare $T$, Lithell $H$, Selinus I, Berne C: Sensitivity to insulin during treatment with atenolol and metoprolol: a randomised, double blind study of effects on carbohydrate and lipoprotein metabolism in hypertensive patients. Bmj 1989, 298:1152-1157.

22. Bell DS, Bakris GL, McGill JB: Comparison of carvedilol and metoprolol on serum lipid concentration in diabetic hypertensive patients. Diabetes Obes Metab 2009, 11:234-238.

23. Haas SJ, Vos T, Gilbert RE, Krum H: Are beta-blockers as efficacious in patients with diabetes mellitus as in patients without diabetes mellitus who have chronic heart failure? A meta-analysis of large-scale clinical trials. Am Heart J 2003, 146:848-853.

24. Konishi M, Haraguchi G, Kimura S, Inagaki H, Kawabata M, Hachiya H, Hirao K, Isobe M: Comparative effects of carvedilol vs bisoprolol for severe congestive heart failure. Circ J 2010, 74:1127-1134.

doi:10.1186/1475-2840-11-14

Cite this article as: Wai et al:: Beta blocker use in subjects with type 2 diabetes mellitus and systolic heart failure does not worsen glycaemic control. Cardiovascular Diabetology 2012 11:14.

\section{Submit your next manuscript to BioMed Central and take full advantage of:}

- Convenient online submission

- Thorough peer review

- No space constraints or color figure charges

- Immediate publication on acceptance

- Inclusion in PubMed, CAS, Scopus and Google Scholar

- Research which is freely available for redistribution

Submit your manuscript at www.biomedcentral.com/submit
Ciomed Central 